\title{
A VALORIZAÇÃO DO TRABALHO ARTÍSTICO HUMANO: UM ESTUDO DE CASO ACERCA DO DIREITO ATRAVÉS DAS ARTES E DAS ÁREAS PÚBLICAS
}

\author{
THE VALUATION OF ARTISTIC HUMAN LABOR: A CASE STUDY ABOUT THE \\ LAW THROUG PUBLIC ARTS AND AREAS
}

${ }^{1}$ Felipe Ferreira Araújo

\section{RESUMO}

O presente artigo busca demonstrar que, em razão do seu alcance social, da sua importância cultural e da disciplina normativa que emana da Constituição de 1988, a arte de rua que ocorre em sua forma pública deve ser garantida pelo Estado, e que ele, enquanto responsável, deverá apoiar tais manifestações culturais, através da criação de políticas públicas que, efetivamente, promovam a arte, procurando sempre remediar os entraves de natureza tributária e administrativa que possam criar obstáculos para a utilização dos espaços urbanos públicos mínimos já destinados à realização da arte pública.

Palavras-chave: Arte pública, Espaços públicos, Estado e responsabilidade, Valorização do trabalho humano

\begin{abstract}
This article seeks to demonstrate that, because of its social importance, its cultural importance and normative discipline emanating from the 1988 Constitution, street art that occurs in its public form must be guaranteed by the state, and that, while responsible, should support such cultural events through the creation of public policies that effectively promote art, always seeking to remedy the obstacles to tax and administrative nature which may create obstacles to the use of minimum public urban spaces already allocated to the realization of public art.
\end{abstract}

Keywords: Public art, Public spaces, State and responsibility, Valuation of human labor

\footnotetext{
${ }^{1}$ Mestrando em andamento em Ciência Jurídica pela Universidade Estadual do Norte do Paraná - UENP, Paraná (Brasil). Professor pela Universidade Estadual do Norte do Paraná - UENP, Paraná (Brasil).

E-mail: felipefeara@outlook.com
} 


\section{CONSIDERAÇÕES INICIAIS}

Vislumbrando-se as mais diversas áreas do conhecimento, não é difícil observar a frequente incidência de inúmeras pesquisas sobre um rol temático quase sempre muito limitado; e com o Direito não poderia ser diferente.

Não há problema algum em desenvolver teorias que ataquem o campo técnico do Direito. No entanto, é fato que boa parte da doutrina jurídica já se encontra saturada dessa mesma dogmática, enquanto que raramente se toca em temas tão essenciais e socialmente importantes para o Direito como a cultura.

Fala-se muito em patrimônio ou em processo e discute-se pouco sobre a educação, mas raramente se toca na arte e, quando muito, a cultura é apenas um sub-tópico dos capítulos finais de um trabalho que a comunidade jurídica, tão negativamente influenciada pelo ensino bancário do Direito, já está exausta em reler.

Longe de querer questionar a importância do debate de temas da esfera privada ou de recortes didáticos mais voltados para a técnica processual jurídica, o presente artigo busca, portanto, acalorar o diálogo entre o Direito e a Arte, com o intuito de se estreitar as relações humanas compreendidas entre essas duas áreas do conhecimento.

Tratando-se de dois campos aparentemente tão distintos e incomunicáveis, será traçada uma ponte - cujas estruturas se encontram forjadas pelos conceitos de demanda social cultural e de arte pública - para que se possa iniciar a construção do mencionado diálogo.

Após, serão analisadas as circunstâncias de um estudo de caso, ocorrido na cidade de Londrina, bem como as responsabilidades do Estado quanto ao cumprimento dos direitos e das garantias fundamentais que interessam ao presente artigo.

Esta análise será imprescindível para a correlação dos conceitos finais, que tornarão possíveis o embasamento teórico de algumas importantes conclusões acerca da complexa relação entre a Arte, o Estado e os espaços públicos, e entre esta mesma tricotomia e o princípio da valorização do trabalho humano.

\section{CULTURA EM CRISE}

Muito embora pertença à Economia o conceito de demanda, não pareceu haver entraves ao Direito para atribuir a ele um novo significado, quando de sua aplicação na esfera processual. Em suma, o referido vocábulo se deriva do verbo latino demandare, que se traduz 
na ação de "confiar" ou de "cometer". Partindo-se da prática jurídica, utiliza-se o mencionado termo para se tratar:

(...) do ato pelo qual uma pessoa confia ou entrega ao julgamento do poder judiciário a solução do direito, que se encontra prejudicado ou ameaçado de perturbação, formulando, assim, o seu pedido, fundado no legítimo interesse de agir. A demanda informa, portanto, a exata ideia da movimentação da ação que vem assegurar o direito violado ou ameaçado ${ }^{1}$.

Contudo, também pode uma demanda advir de um fato ou um de valor de detecção das necessidades sociais. Grosseiramente, classifica-se como social a demanda que indicar todo e qualquer somatório das necessidades reais dos indivíduos que venham a compor um segmento específico da sociedade.

A demanda social, portanto, elenca ou relaciona os assuntos e os problemas sobre os quais o governo e os cidadão a ele vinculados concentram a sua atenção, em um determinado momento da história² .

Por este viés, a prática cotidiana permite afirmar que a cultura tem se mostrado não apenas uma necessidade de grande caráter social como também a demanda menos contemplada pelas diretrizes orçamentárias estabelecidas pelo poder público. É notável a crise experimentada pelo atual cenário cultural brasileiro. São poucos os municípios, afastados dos grandes centros urbanos, que ainda oferecem aos seus cidadãos algum programa eficaz de incentivo à cultura.

Somado a este fator, tem se tornado cada vez mais comum aos profissionais da área, que em muito dependem da manutenção periódica desses programas, assistirem da primeira fila repentinos cortes orçamentários, cujos valores eram antes destinados à satisfação das demandas sociais culturais de grande parcela da comunidade.

Exemplificando-se; em janeiro de 2013, o orçamento total de seis milhões e seiscentos mil reais destinados ao Programa Municipal de Incentivo à Cultura da cidade de Londrina, vulgo PROMIC, Estado do Paraná, sofreu um abrupto corte de aproximadamente dois milhões de reais, em razão do plano de contingenciamento definido pela Prefeitura, atingindo 30\% do total das verbas da pasta ${ }^{3}$.

Paralelamente, observa-se também uma enorme falta de critérios quando o governo federal concede o aval para que se invista valores exorbitantes em eventos classificados como “culturais", mas que, notoriamente, fogem às propostas que tangenciam a melhor utilização do abatimento de impostos e a aplicação mais razoável do dinheiro público.

\footnotetext{
${ }^{1}$ SLAIBI FILHO, Nagib; CARVALHO, Gláucia. Vocabulário jurídico conciso. 2. ed. Rio de Janeiro, Forense, 2010. pp. 245 e 246.

${ }^{2}$ BAPTISTA, T. W. F.; REZENDE, M. A ideia de ciclo na análise de políticas públicas. In MATTOS, R. A.; BAPTISTA, T. W. F. Caminhos para análise das políticas de saúde. 2011. p. 143.

3 LUPORINI, Fábio. No fio da tesoura. Jornal de Londrina. Londrina, 20 de janeiro de 2013. Fonte online disponível em <http://www.jornaldelondrina.com.br/online/conteudo.phtml?tl=1\&id=1337136\&tit=No-fio-datesoura>.
} 
Exemplificando-se mais uma vez; em agosto de 2014, um projeto de aproximadamente $\mathrm{R}$ \$ 4,1 milhões destinados aos shows do cantor e compositor Luan Santana foi aprovado pelo Ministério da Cultura, vulgo MinC, para a captação de recursos via Lei Rouanet. O aval foi dado pela Comissão Nacional de Incentivo à Cultura (CNIC).

A verba previa a manutenção de quinze shows da turnê "Nosso tempo é hoje", do jovem cantor sertanejo. Uma das justificativas dadas ao governo cita buscar difundir as raízes sertanejas enquanto manifestação cultural e artística a partir da música romântica ${ }^{4}$.

\section{ARTE DE RUA}

Dentre as mais diversas demandas sociais culturais, talvez exista uma modalidade que mereça mais atenção por parte do Estado do que as outras; não apenas em razão dos baixos investimentos públicos e privados destinados a ela, mas também porque essa forma de manifestação cultural é capaz de satisfazer outras necessidades sociais, fomentando, em um único ato, a concretização de determinados direitos e garantias fundamentais. Trata-se da arte de rua.

O teatro de rua se encontra agregado às raízes das mais autênticas manifestações da identidade cultural nacional e comporta uma gama de espetáculos que utilizam as mais diversificadas linguagens, tal como a dança e o canto e a presença de atores ou de bonecos.

Estão vinculadas a essas bases populares - ou constantemente partindo de outras inquietações - experiências mais contemporâneas, a exemplo dos processos de encenação e representação de Bertold Brecht ou das investigações do real significado do termo "ator", desenvolvidas pelo teatro antropológico de Eugênio Barba 5 .

\subsection{Arte em espaços públicos}

Através de algumas das mais instigantes técnicas de seu "Teatro do Oprimido", Augusto Boal utiliza, até os dias de hoje, as ruas e as praças para realizar o seu "teatro fórum".

\footnotetext{
${ }^{4}$ ORTEGA, Rodrigo. MinC aprova projeto de $R \$ 4,1$ milhões para turnê de Luan Santana. G1. São Paulo, 11 de agosto de 2014. Fonte online disponível em <http://g1.globo.com/musica/noticia/2014/08/minc-aprova-projetode-r-41-milhoes-para-turne-de-luan-santana.html $>$.

${ }^{5}$ CRUCIANI, Fabrizio; FALLETTI, Clelia. Teatro de rua. Tradução de Roberta Baarni. 1. ed. São Paulo: Hucitec, 1999. pp. 143/145.
} 
Anexadas ao artesanato, ao hip-hop e ao skate, estão, portanto, as manifestações culturais politizadas que ocorrem em sua forma pública.

Contudo, o mero teatro de rua em si não é capaz de preencher toda a amplitude conceitual aqui discutida, até mesmo porque o conceito e a extensão da arte devem ser constantemente repensados.

A expressão "arte pública" se insere oficialmente no vocabulário da crítica de arte em meados da década 1970, seguindo as políticas de financiamento criadas por parte do Estado para fomentar a arte em espaços públicos ${ }^{6}$.

Ressalta-se que, do ponto de vista físico e urbano, o Dicionário de Urbanismo de Françoise Choay e Pierre Merlin define o espaço público como a parte de domínio público não edificado e destinado aos usos públicos.

Atualmente, os movimentos legítimos dos artistas de rua ${ }^{7}$ classificam como pública:

(...) toda e qualquer forma de arte fisicamente acessível, que modifica a paisagem circundante de modo temporário ou permanente. Trata-se da manifestação artística que busca alterar e se integrar à paisagem original, interferindo na fisionomia urbana, recuperando espaços públicos degradados e promovendo, assim, o debate cívico. Afinal, o artista público é um cidadão em primeiro lugar ${ }^{8}$.

Essa classificação parte de algumas das indagações essenciais sobre a modalidade teatral na qual o artista Amir Haddad se insere: o teatro de rua. A busca de um conceito sólido para o tema motivou importantes reflexões e permitiu rascunhar a natureza desse formato de manifestação cultural.

\subsection{Arte pública: acessos e entraves}

Todavia, por que a arte pública deve merecer uma atenção mais imediata por parte do Estado do que as demais manifestações culturais?

A resposta para esse questionamento é curiosamente simples: o fazer artístico em sua forma pública transcende a mera encenação em espaços e logradouros coletivos. Ao interferir na fisionomia urbana, a arte pública torna democraticamente possível o acesso à cultura.

\footnotetext{
${ }^{6}$ CHOAY, Françoise; MERLIN, Pierre. Dicionário de urbanismo. França: 1988.

${ }^{7}$ Exemplificando-se; tem-se hoje o Movimento dos Artistas de Rua de Londrina (MARL). Criado em 2012, face ao mal tratamento costumeiramente dado ao teatro de rua pelos órgãos públicos competentes, o Movimento visa estimular discussões de cunho artístico a respeito das políticas destinadas à cultura municipal e regional e garantir o intercâmbio entre os artistas londrinenses que participam do Movimento e os envolvidos em outras organizações culturais ativas pelo país.

${ }^{8} \mathrm{O}$ MARL iniciou as suas atividades disponibilizando em sua página da web e em seu perfil do Facebook uma carta endereçada à sociedade e, em especial, ao poder público. O documento, de redação coletiva, introduz o Movimento perante a sociedade, reafirmando o caráter popular da sua iniciativa. Fonte online disponível em <http://movimentodosartistasderuadelondrina.blogspot.com.br/p/carta-do-movimento-dos-artistas.html>.
} 
Qualquer membro da sociedade, seja qual for o seu poder aquisitivo ou o seu estrato social, poderá apreciá-la, porque essa é uma modalidade gratuita9 .

Ademais, o teatro de rua preocupa-se em dar voz aos excluídos, promovendo o debate acerca de termas que são mais timidamente abordados em outros formatos, tais como os mecanismos de poder, a miséria, a fome e, até mesmo, a morte.

Trata-se, portanto, da utilização lícita e possível de espaços públicos para a formação social; e não de mero entretenimento. Afinal, não há lugar mais democrático para se discutir a cidadania do que na rua. Dessa forma, a arte pública se mostra capaz de promover o debate cívico e de fomentar, ao mesmo tempo, direitos e garantias fundamentais previstos pela Constituição da República Federativa do Brasil de 1988, tais como:

(i) A dignidade da pessoa humana (Art. $1^{\circ}$, inciso III) que, em decorrência de fatores sócio econômicos, não tem acesso às fontes de cultura;

(ii) A livre manifestação do pensamento (Art. $5^{\circ}$, inciso IV) dos dramaturgos e diretores que dedicam o seu tempo a escrever os textos de relevância social que serão encenados para a comunidade;

(iii) A livre expressão da atividade intelectual, artística, científica e de comunicação (Art. $5^{\circ}$, inciso IX);

(iv) O livre exercício do trabalho dos artistas envolvidos nas apresentações (Art. $5^{\circ}$, inciso XIII) e, finalmente;

(v) A possibilidade de reunião pacífica, sem armas, em locais abertos ao público (Art. $5^{\circ}$, inciso XVI).

Há, porém, um indesejável entrave. A arte pública não é capaz de se desvencilhar das políticas administrativas estatais, pois, tal como outras inúmeras iniciativas de caráter popular, está sujeita às leis e às permissões do Direito que norteiam as relações humanas do plano social. Essa sujeição vincula, de maneira inevitável, o fazer artístico em sua forma pública à necessidade de concessões, por parte do Poder Executivo, e de formalizações, por parte do Poder Legislativo.

Esse seria, portanto, um calcanhar de Aquiles. Ao abordar o tema, o artista de rua Antônio Sobreira se mostra categórico ao afirmar que se fosse possível escolher, a única dependência a que deveríamos [os artistas de rua] estar sujeitos seria a do público.

${ }_{9}$ TURLE, Licko. $O$ teatro de rua é arte pública: uma possivel apropriação de conceito de Amir Haddad e do grupo Tá Na Rua.p. 12. 


\section{LONDRINA: UM PROFUNDO ESTUDO DE CASO}

Com o processo de municipalização das fiscalizações de trânsito, disciplinadas pelo Código de Trânsito Brasileiro, foi aprovada, em Londrina, a Lei Municipal nº 8.191, de 19 de junho de 2000, que atribuiu à Companhia Municipal de Urbanização a competência para o gerenciamento do transporte coletivo e das ações de desenvolvimento urbano planejadas para toda a cidade.

Essa nova atribuição, ocasionou na alteração do nome institucional da antiga COMURB, que passou a se chamar Companhia Municipal de Trânsito e Urbanização, também conhecida como CMTU.

A Companhia Municipal de Trânsito e Urbanização se instituiu como sociedade de economia mista e capital autorizado. Nesse sentido, leciona Hely Lopes Meirelles que:

Embora pertencendo à Administração indireta, a sociedade de economia mista ostenta estrutura e funcionamento de empresa particular, porque isto constitui, precisamente, sua própria razão de ser. Nem se compreenderia que se burocratizasse tal sociedade a ponto de emperrar-lhe os movimentos e a flexibilidade mercantil, com os métodos estatais ${ }^{10}$.

Deste modo, busca-se conciliar as estruturas da empresa privada com os objetivos do interesse público. Em outras palavras, as sociedades de economia mista admitem o lucro como o principal rendimento da exploração da atividade econômica.

No caso da CMTU, o exercício do poder de polícia administrativa, quando da aplicação de multas de trânsito, se mostra a sua principal fonte de lucro.

O poder de polícia supracitado é classificado pela doutrina nacional majoritária como o instrumento através do qual a administração pública, fundada no princípio da supremacia do interesse público, condiciona o exercício de determinadas atividades, restringindo, assim, o uso e o gozo de bens e de direitos pelos particulares por intermédio de ações de fiscalização, tanto preventivas quanto repressivas.

Trata-se da autotutela administrativa, cujas atribuições fundam-se na discricionariedade, que se traduz na livre escolha da oportunidade e conveniência para o exercício deste poder; na auto-executoriedade, ou seja, a faculdade de decidir e executar diretamente sua decisão por seus próprios meios e, por fim; na coercibilidade, isto é, a imposição coativa das medidas adotadas pela administração ${ }^{11}$.

\footnotetext{
${ }^{10}$ MEIRELLES, Hely Lopes. Direito administrativo brasileiro. 37. ed. São Paulo: Malheiros Editores, 2011. p. 408.

${ }^{11}$ MELLO, Celso Antônio Bandeira de. Curso de direito administrativo brasileiro. 17. ed. São Paulo: Malheiros Editores, 2004. pp. 732/738.
} 
Desta forma, são editadas leis por parte do poder público e expedidos regulamentos e instruções que fixam as condições e os requisitos para o uso da propriedade e para o exercício das atividades que devem ser policiadas. Após as verificações necessárias, é outorgado o respectivo alvará de licença ou autorização, seguido pela fiscalização competente.

Assim, tal como prevê a Lei Municipal nº 5.496/93, em complemento com as alterações feitas pela Lei Municipal nº 8.191/2000:

Art. $5^{\circ}$. Compete à Companhia Municipal de Trânsito e Urbanização - CMTU-LD:

(...)

IV - Explorar economicamente e administrar, mediante delegação específica do Executivo, os mercados municipais, quiosques e todas as demais atividades desenvolvidas em vias, logradouros e equipamentos públicos, constituindo-se em permissionária desses serviços e podendo, por meio de processo licitatório, delegá-los a terceiros;

Pois bem; havendo todo esse respaldo legal, também foi atribuído à CMTU, munida de seu poder de polícia administrativa, fiscalizar a obediência das disposições do recente Código de Postura do Município; lei municipal intimamente atrelada às manifestações artísticas de que se trata este artigo.

\subsection{Código de Postura}

Nos termos do seu art. $1^{\circ}$, o Código de Postura do Município de Londrina estatui as necessárias relações entre o poder público local e as pessoas físicas ou jurídicas, liberando, fiscalizando, condicionando, restringindo ou impedindo a prática ou omissão de atos de particulares e disciplinando o funcionamento de estabelecimentos comerciais, industriais, de produção e de prestação de serviços, sempre no sentido de disciplinar e manter a ordem, a higiene, a moral, o sossego e a segurança pública.

Seu Título III dispõe sobre a polícia administrativa de costumes, segurança, ordem, moralidade e do sossego público. Em seu respectivo Capítulo II, cuida-se dos divertimentos públicos que, para os efeitos desta lei, nada mais são do que festas, congressos, reuniões de caráter empresarial, político, científico, cultural, religioso e social, espetáculos de qualquer natureza, shows, exposições, circos, competições esportivas ou de destreza e similares, reuniões dançantes e outros acontecimentos ou atividades assemelhadas. Adiante, determina o art. 26 que:

Para a realização de evento de qualquer natureza, rural ou urbano, com cobrança ou não de ingresso, aberto ao público em geral, é necessária a obtenção de autorização, solicitada com antecedência mínima de 07 (sete) dias úteis da data da efetiva realização, junto ao Município. 
Com base no mesmo texto legal, o Município também estabelecerá as condições que julgar convenientes para garantir à segurança, a ordem, a moralidade e o sossego público de seus frequentadores e da vizinhança, devendo o interessado preencher os requisitos definidos em decreto. Importa ressaltar que a autorização destinada a realização do evento poderá ser revogada a qualquer tempo, tão cedo quanto for constatada qualquer irregularidade.

Mas, talvez, a regra mais intrigante seja aquela contida na norma do art. 29, ao se estabelecer que a mencionada autorização será expedida após a quitação dos tributos municipais devidos, relacionados ao evento, previstos no Código Tributário Municipal.

Em outras palavras, para que seja possível realizar qualquer manifestação cultural em vias e logradouros públicos da cidade de Londrina, são necessárias não só a obtenção de autorizações com antecedência mínima de sete dias úteis, como também o recolhimento de tributos, sob pena de violação à lei municipal.

\subsection{Inconstitucionalidades}

Primeiramente, cabe dizer que é pacífico o entendimento doutrinário de que o poder de polícia administrativa se restringe às funções da administração pública. Doutrina e jurisprudência caminham juntas disciplinando a ausência de legitimidade quando da atribuição da ação de polícia aos particulares.

Logo, delegar à CMTU, enquanto sociedade de economia mista, uma atribuição que, até então, pertencia ao município, contribui para que o poder de polícia administrativa possa vir a atender interesses particulares que, de fato, não traduzam a supremacia do real interesse público.

A principal lide, de que se tem notícia, discutindo acerca desta matéria, refere-se a Ação Civil Pública n . 2002.70.01.030279-6/PR, proposta pela Subseção de Londrina da Ordem dos Advogados do Brasil. A pretensão desta ação buscava anular todas as autuações lavradas pela referida Companhia, em razão da não presunção de legitimidade do seu poder de polícia.

A parte autora sustentou a tese de que, em acordo com o majoritário entendimento, não se admite delegar aos particulares as ações decorrentes do poder de polícia administrativa. Ainda que o capital de uma sociedade de economia mista seja quase que totalmente público, não se pode negar que parte do montante arrecadado passe para o domínio de particulares. Trata-se, portanto, de uma polêmica contrariedade.

Em segundo lugar, cabe ressaltar que a doutrina defende piamente o fato de que os limites do poder de polícia administrativa são: 
(...) demarcados pelo interesse social em conciliação com os direitos fundamentais do indivíduo assegurados na Constituição de República (art. $5^{\circ}$ ). Vale dizer, esses limites decorrem da Constituição Federal, de seus princípios e da lei. Do absolutismo individual evoluímos para o relativismo social ${ }^{12}$.

Ora; para o caso em tela, não há dúvidas quanto ao caráter fundamental do direito à cultura, da sua correlação ao princípio da dignidade da pessoa humana e, portanto, da evidente inconstitucionalidade presente nas disposições legais supracitadas.

\section{ESTADO E RESPONSABILIDADE}

Resta claro haver uma complexa, e inesperada, relação entre a Arte, o Estado e os espaços públicos; e este envolvimento parece ser ainda mais dinâmico quando o primeiro termo desse trinômio acontece em sua forma pública, tal como foi exposto acima.

Contudo, qual seria, de fato, a responsabilidade do Estado enquanto elemento integrante dessa calorosa relação? Até que ponto se pode conferir ao Estado o dever de concretizar o direito social à cultura? Aliás, seria a cultura um direito social?

Em suma, quais seriam as dimensões da responsabilidade do Estado, para com a sociedade civil, quando está em pauta a arte pública?

Todas essas são indagações importantes, mas antes de buscar responde-las, é necessário esclarecer que a arte classificada como pública ganha essa qualidade porque se mostra fisicamente acessível a todos, e não porque o seu precursor seja, necessariamente, o poder público; o que, por outro lado, não esquiva a figura do Estado do dever de cumprir as determinações normativas que serão expostas a seguir.

Também é necessário esclarecer que a cultura é um direito social. Aliás, essa construção jurídica se mostra pacífica tanto pela doutrina quanto pela jurisprudência.

Em sua obra, José Afonso da Silva defende que, muito embora os direitos culturais não tenham sido arrolados no corpo do Art. $6^{\circ}$, da Constituição Federal de 1988 - que traz a disciplina acerca dos direitos sociais - se a educação o foi aí também estarão aqueles. Até mesmo porque:

(...) estão explicitamente referidos no caput do Art. 215, consoante o qual o Estado garantirá a todos o pleno exercício dos direitos culturais. Por aí também se vê que se tratam de direitos informados pelo princípio da universalidade, isto é, direitos garantidos a todos ${ }^{13}$.

\footnotetext{
${ }^{12}$ MEIRELLES, Hely Lopes. Direito administrativo brasileiro. 37. ed. São Paulo: Malheiros Editores, 2011. p. 139.

${ }^{13}$ SILVA, José Afonso da. Curso de direito constitucional positivo. 33. ed. São Paulo: Malheiros Editores, 2010. pp. 313 e 314.
} 
Com igual força normativa, disciplina o Art. 216, incisos I e II, da Lei Maior, que as formas de expressão também se constituem como patrimônio cultural brasileiro de natureza imaterial, quando tomadas individualmente ou em conjunto, portando referências à identidade, à ação e à memória dos diferentes grupos formadores da sociedade brasileira.

O conjunto dessas disposições se mostra, portanto, suficiente para ao menos levantar a correlação temática inicialmente pretendida: cabe ao Estado assegurar a todos o pleno exercício dos direitos culturais.

\section{A VALORIZAÇÃO DO TRABALHO ARTÍSTICO HUMANO}

Pelos arredores do texto constitucional, encontra-se diluída a proteção do trabalho humano.

Ao contrário do que normalmente se pensa, as bases da valorização do trabalho humano não estão apenas contidas no caput do Art. 170, mas também nos Arts. $1^{\circ}$, inciso IV; $3^{\mathrm{o}}$; do $5^{\mathrm{o}}$ ao $11^{\mathrm{o}} ; 24$, inciso I e 37 , inciso XIX. Igualmente integrado a este rol normativo está o Art. 193, cuja disposição geral disciplina a chamada ordem social ${ }^{14}$.

Todas estas disposições sintetizam o conceito que enaltece a importância do trabalho humano, e, por isso, devem ser interpretadas de maneira harmônica, sob pena de se produzir entendimentos meramente casuísticos.

\subsection{Principiologia}

O conflito entre o capital e o trabalho nunca esteve tão em alta. Em meio a isso, ao se abraçar a dignidade da pessoa humana enquanto princípio, a Constituição da República de 1988 abarca duas definições distintas a respeito: (i) a de direito individual visando à proteção e (ii) a de dever de tratamento igualitário, ou seja, o dever de respeitar a dignidade do outro enquanto direito fundamental.

Concomitantemente, observa-se o princípio do valor social do trabalho iluminando a interpretação e a aplicação do Direito que trata o trabalhador enquanto cidadão inserido em uma sociedade que se almeja mais justa e igualitária.

\footnotetext{
${ }^{14}$ OLIVEIRA, Lourival José de. Direito do trabalho segundo o princípio da valorização do trabalho humano: estudos dirigidos para alunos de graduação. São Paulo: LTr, 2011. p. 25.
} 
Desta feita, não é difícil concluir que os princípios da dignidade da pessoa humana e do valor social do trabalho foram colocados lado a lado no texto constitucional porque revelam o caminhar social contínuo para a concretização do Estado Democrático de Direito.

Defendem alguns que a correta leitura constitucional do princípio da valorização do trabalho humano está ligada intrinsecamente com o emprego, porque este seria a única forma de coerência com os demais imperativos principiológicos constitucionais, tais como os princípios da justiça social e da busca do pleno emprego, conforme os ditames do Art. 170, inciso VIII ${ }^{15}$. Lado outro, há quem defenda uma ideia contrária, alegando que:

(...) não se pode desconsiderar que o valor social do trabalho abrange, em especial, a ideia de dar ao homem a oportunidade de, exercendo a sua liberdade, optar por um projeto de vida e, por meio do seu trabalho, poder concretizá-lo. Assim, o princípio do valor social do trabalho tem como núcleo também a ideia de liberdade, que é o anseio mais profundo do homem moderno. Não há como se admitir respeitado esse princípio se o homem não é verdadeiramente livre ${ }^{16}$.

Em outras palavras, depreende-se que o trabalhador - e não necessariamente o empregado - tem sido visto como merecedor de determinadas proteções, sobretudo pelo papel que desempenha na sociedade. Nos ensinamentos de Bocorny:

A valorização do trabalho humano, esclareça-se, não somente importa em criar medidas de proteção ao trabalhador, como foi destacado nos Estados Sociais. (...) o grande avanço do significado do conceito que se deu no último século foi no sentido de se admitir o trabalho (e o trabalhador) como principal agende de transformação da economia e meio de inserção social, por isso, não pode ser excluído do debate relativo às mudanças das estruturas de uma sociedade. Assim, o capital deixa de ser o centro dos estudos econômicos, devendo voltar-se para o aspecto, talvez subjetivo, da força produtiva humana ${ }^{17}$.

Ao se tratar do trabalho humano, deve-se, portanto, ter em mente o conceito de labor em seu sentido mais amplo, e não uma ideia de atividade restrita e prestada apenas mediante um vínculo empregatício.

É preciso, enfim, classificar todo e qualquer ofício desenvolvido pelo homem enquanto gênero do qual a profissão assalariada é apenas uma espécie.

\subsection{Trabalho artístico humano}

Superado o entendimento acima, também é necessário esclarecer que, partindo-se de preceitos morais e filosóficos, o trabalho humano se mostra historicamente como um meio

\footnotetext{
${ }^{15}$ DELGADO, Maurício Godinho. Princípios do direito individual e coletivo do trabalho. 2. ed. São Paulo: LTr, 2004. p. 36.

16 PINHO, Daniella Ribeiro de. A valorização do trabalho humano como pilar do estado democrático de direito. JusNavegandi.com. $1^{\mathrm{a}}$ jan. 2011. Fonte online disponível em <http://jus.com.br/revista/texto/18466/a-valorizacaodo-trabalho-humano-como-pilar-do-estado-democratico-de-direito >

17 BOCORNY, Leonardo Raupp. A valorização do trabalho humano no estado democrático de direito. Porto Alegre: SAFE, 2003. pp. 42 e 43.
} 
capaz de se efetivar a realização espiritual e a produção, satisfazendo, assim, outras necessidades humanas ${ }^{18}$.

Ora; a arte é um ofício e, tal como qualquer outra atividade exercida pelo homem, o fazer artístico pode muito bem se enquadrar no conceito de trabalho humano.

Logo, todo trabalhador ator que realiza a sua arte deve ter preservada a sua dignidade e assegurados os seus direitos fundamentais.

Indiscutivelmente, esta segurança jurídica deve ser garantida pelo Estado enquanto prestação positiva.

A partir desta construção argumentativa e das circunstâncias trazidas pelo estudo de caso descrito acima, torna-se inegável que cercear produção e a exibição da arte pública afronta não só a dignidade da pessoa humana do artista, mas também a valorização do seu próprio trabalho.

\section{CONCLUSÕES}

Alcançado o apogeu do teatro elisabetano, defendeu William Shakespeare: tratai bem os atores, pois eles são a crônica e o breve resumo dos tempos.

Aí se esconde a essência da arte pública: a sua enorme capacidade de resumir a realidade social dos dias atuais, afim de que as circunstâncias do hoje possam levar ao público a reflexão e consequente debate cívico.

Dessa forma, em razão do seu alcance social, da sua importância cultural e da disciplina normativa que emana da Constituição de 1988, a arte de rua que ocorre em sua forma pública deve ser, portanto, garantida pelo Estado, e ele, enquanto responsável pela sua concretização, deverá apoiar tais manifestações culturais, através da criação de políticas públicas que, efetivamente, fomentem a arte.

Também cabe ressaltar que, tal como é possível depreender do estudo de caso em tela, para que possam ser plenamente alcançadas as dimensões da responsabilidade do Estado, cabe também ao Poder Executivo buscar remediar os entraves de natureza tributária e administrativa que possam criar obstáculos para a utilização dos espaços urbanos públicos mínimos já destinados à realização da arte pública, vez que sozinha ela não é capaz de se desvencilhar das políticas administrativas estatais e das concessões do Poder Legislativo.

${ }^{18}$ STUCHI, Victor Hugo Nazário. A valorização do trabalho humano como forma de realização da justiça social. Olímpia: Scientia FAER, Ano 2, Vol. 2, 2010. pp. 138 e 139. 
Em Londrina - cenário do estudo de caso apresentado por este artigo - o conflito entre as disposições legais do Código de Postura do Município e as demandas pela utilização das vias e dos logradouros públicos ainda não foi sanado.

Contudo, motivado pelas evidentes contrariedades ao ordenamento jurídico pátrio, contidas nas disposições do referido Código, o Movimento dos Artistas de Rua de Londrina somado a inúmeros outros cidadãos londrinenses, artistas e não artistas - tratou, o quanto antes, de tomar as devidas providências, com o intuito de se levar o problema ao legislativo municipal e aos demais órgãos competentes.

O que se pretende, em parceria com toda a sociedade, é a elaboração de um projeto de lei que, a exemplo de outros, seja capaz de alterar as disposições do Código de Postura do Município de Londrina, destinadas à disciplina desse tema, e de pôr fim a burocratização do acesso à cultura municipal, promovendo-se, a partir disso, a arte em sua forma pública.

Como já bem exposto, toda arte de rua que se almeja pública é, necessariamente, desinteressada de qualquer fim mercantil ou comercial, se forem levados em conta fatores de natureza capitalista.

Dessa forma, por óbvio, não há que se falar em "renúncia de receita" para os cofres públicos, se o fato gerador deste tributo não alcança a tipicidade dessas manifestações culturais pautadas no conceito gratuidade.

Este mesmo entendimento tem motivado, inclusive, a criação de diversos outros projetos de lei espalhados pelo país que, em suma, isentam os artistas de rua - principalmente aqueles não contemplados por repasses de programas de incentivo à cultura - do pagamento de tributos para o uso de espaços públicos, à exemplos das cidades de São Paulo e do Rio de Janeiro.

\section{REFERÊNCIAS BIBLIOGRÁFICAS}

BAPTISTA, T. W. F.; REZENDE, M. A ideia de ciclo na análise de políticas públicas. In MATTOS, R. A.; BAPTISTA, T. W. F. Caminhos para análise das políticas de saúde. 2011.

BOCORNY, Leonardo Raupp. A valorização do trabalho humano no estado democrático de direito. Porto Alegre: SAFE, 2003.

BRASIL. Código de Trânsito Brasileiro. 1997.

BRASIL. Constituição da República Federativa do Brasil. 1988.

CHOAY, Françoise; MERLIN, Pierre. Dicionário de urbanismo. França: 1988. 
CRUCIANI, Fabrizio; FALLETTI, Clelia. Teatro de rua. Tradução de Roberta Baarni. 1. ed. São Paulo: Hucitec, 1999.

DELGADO, Maurício Godinho. Princípios do direito individual e coletivo do trabalho. 2. ed. São Paulo: LTr, 2004.

LONDRINA. Lei Municipal no. 5.496/1993.

LONDRINA. Lei Municipal no $8.191 / 2000$.

LONDRINA. Lei Municipal nº 11.468/2011.

LUPORINI, Fábio. No fio da tesoura. Jornal de Londrina. Londrina, 20 de janeiro de 2013. Fonte online disponível em $<$ http://www.jornaldelondrina.com.br/online/conteudo.phtml?tl=1\&id=1337136\&tit=No-fioda-tesoura>.

MEIRELLES, Hely Lopes. Direito administrativo brasileiro. 37. ed. São Paulo: Malheiros Editores, 2011.

MELLO, Celso Antônio Bandeira de. Curso de direito administrativo brasileiro. 17. ed. São Paulo: Malheiros Editores, 2004.

MOVIMENTO DOS ARTISTAS DE RUA DE LONDRINA (MARL). Carta à sociedade e ao poder público de Londrina. Londrina, 06 de março de 2012. Fonte online disponível em $<$ http://movimentodosartistasderuadelondrina.blogspot.com.br/p/carta-do-movimento-dosartistas.html>.

OLIVEIRA, Lourival José de. Direito do trabalho segundo o princípio da valorização do trabalho humano: estudos dirigidos para alunos de graduação. São Paulo: LTr, 2011.

ORTEGA, Rodrigo. MinC aprova projeto de $R \$ 4,1$ milhões para turnê de Luan Santana. G1. São Paulo, 11 de agosto de 2014. Fonte online disponível em $<$ http://g1.globo.com/musica/noticia/2014/08/minc-aprova-projeto-de-r-41-milhoes-paraturne-de-luan-santana.html $>$.

PINHO, Daniella Ribeiro de. A valorização do trabalho humano como pilar do estado democrático de direito. JusNavegandi.com. $1^{\text {a }}$ jan. 2011. Fonte online disponível em $<$ http://jus.com.br/revista/texto/18466/a-valorizacao-do-trabalho-humano-como-pilar-doestado-democratico-de-direito $>$

SILVA, José Afonso da. Curso de direito constitucional positivo. 33. ed. São Paulo: Malheiros Editores, 2010.

SLAIBI FILHO, Nagib; CARVALHO, Gláucia. Vocabulário jurídico conciso. 2. ed. Rio de Janeiro, Forense, 2010. pp. 245 e 246.

SOBREIRA, Antônio. Políticas estatais para a cultura e arte pública: vale cultura em xeque. STUCHI, Victor Hugo Nazário. A valorização do trabalho humano como forma de realização da justiça social. Olímpia: Scientia FAER, Ano 2, Vol. 2, 2010. pp. 138 e 139.

TURLE, Licko. O teatro de rua é arte pública: uma possível apropriação de conceito de Amir Haddad e do grupo Tá Na Rua. 